\title{
Gold nanoparticles enhanced fluorescence for highly sensitive biosensors based on localized surface plasmon resonance applied in the determination C-reactive protein
}

\author{
Phuong Que Do Tran ${ }^{1,2 \#}$, Tran Duc Trung 2,3\#, Bach Thang Phan ${ }^{1,2,4}$, Hanh Kieu Thi Ta ${ }^{1,2,3}$, Ngoc Xuan Dat Mai ${ }^{1,2}$, \\ Lai Thi Hoa ${ }^{1,2}$, Thanh Van Thi Tran ${ }^{2,3}$, Dung Van Hoang ${ }^{2,4}$, Nhu Hoa Thi Tran ${ }^{2,3}{ }^{*}$
}

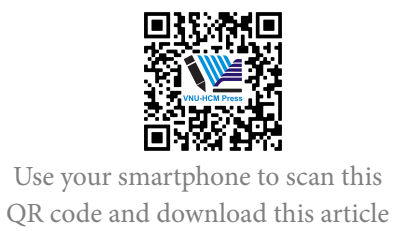

\#These authors contributed equally

${ }^{1}$ Center for Innovative Materials and Architectures (INOMAR), HoChiMinh City, Viet Nam

${ }^{2}$ Vietnam National University, HoChiMinh City, Viet Nam

${ }^{3}$ Faculty of Materials Science and Technology, University of Science, Ho Chi Minh City, Viet Nam

${ }^{4}$ Laboratory of Advanced Materials, University of Science, HoChiMinh City, Viet Nam

Correspondence

Nhu Hoa Thi Tran, Vietnam National University, HoChiMinh City, Viet Nam

Faculty of Materials Science and Technology, University of Science, Ho Chi Minh City, Viet Nam

Email: ttnhoa@hcmus.edu.vn

History

- Received: 2020-11-11

- Accepted: 2021-02-25

- Published: 2021-03-17

DOI : 10.32508/stdj.v24i1.2489

\section{Check for updates}

Copyright

(c) VNU-HCM Press. This is an openaccess article distributed under the terms of the Creative Commons

Attribution 4.0 International license.

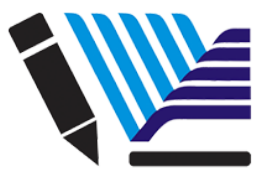

VNU-HCM Press

\begin{abstract}
Introduction: C-reactive protein (CPR) is known as an inflammation marker related to numerous pathology. Optical biosensor based on the fluorescence dyed is widely used in diagnosis. There are still limitations on fluorescence signal detection due to the photobleaching effect. The localized surface plasmon resonance (LSPR) performed by gold nanoparticles (Au NPs) is testified to enhance photo-signal gathered from the dye molecules. The fluorescence enhancement by the effect of Au NPs coating on the luminescence is destined as the evolution of label-based biosensing. Methods: In this study, Au NPs were used for their significant optical properties and biocompatibility additionally. The seed-mediated synthesis method provided stable NPs with all the essential qualities. A series of modification steps were done on a glass substrate before the bio-bonding for fluorescence-based sensing by a transmission mode (T-mode) detection system introduced in Viet Nam. Results: The synthetic Au NPs in the nanosphere structure evinced the absorbance at a maximum wavelength is $521 \mathrm{~nm}$. All the followed alterations showed the accomplishment in forming the in need linking proved through the basic analysis methods. Finally, CRP with the Alexa 488 dye was observed for average at 4.8 folds of enhancement factor compared between the Au NPs coating and non-coating substrate detected by the T-mode system. The low coefficient of variation at under $0.7 \%$ appeared for the repeatability and stability of this sensor. Conclusion: The T-mode system's completely modern approach combined with the LSPR applied in fluorescence sensors enhanced is developed successfully. The future prospect of this designed sensing method is promising by changing the materials' structures and ingredients.
\end{abstract}

Key words: LSPR, gold nanoparticles, fluorescence enhancement, C-reaction protein, optical biosensors

\section{INTRODUCTION}

Label-based biosensors are widely applied in life science and beyond. One of the most powerful utilizations of that rapid and high-performance method is in biomedical fields such as diagnosis of infectious diseases, cancer detection, DNA determination ${ }^{1-3}$, etc. To increase the sensitivity for lower the test limit of detection (LOD), the potential metal nanoparticles (NPs) were used since their outstanding behavior in optical, electrochemical, plasmonic, and radiative properties ${ }^{4-6}$. In this paper, gold nanoparticle (Au NPs) synthesized by Turkevich $\operatorname{method}^{7}$ was investigated for its localized surface plasmon resonance (LSPR) effects in other signal enhancement for a labeled based optical biosensor system applied in Creactive protein (CRP) detection.

Besides other featured optical properties that were mentioned even from the Lycurgus Cup's invention back to the $4^{\text {th }}$ century A.D, localized surface plasmon resonance (LSPR) is an attractive optical phenomenon most found in the noble metal nanostructure. The exceptional ability proved in the absorption of the special incoming light then converts the photon energy into the electrons' oscillation before scattering it with another collective-wavelength outcome light ${ }^{8}$. Therefore, the optical occurrence consisting of photobleaching does not occur as if LSPR happened ${ }^{9}$. Based on the difference in the nanoparticles size, shape, ingredient, and interspace, a large adjustment of LSPR was provided mostly in the maximum absorbance wavelength under the excitation light ${ }^{10}$. Gold was used in our study since its chemical stability forces a wide range of applications and is currently being attended in biosensors ${ }^{11}$.

CRP is known as an inflammation marker significant aggregation in the liver and recommended testing in postoperative infection monitor cases, pathological

Cite this article : Tran P Q D, Trung T D, Phan B T, Ta H K T, Mai N X D, Hoa L T, Tran T V T, Hoang D V, Tran N H T. Gold nanoparticles enhanced fluorescence for highly sensitive biosensors based on localized surface plasmon resonance applied in the determination C-reactive protein. Sci. Tech. Dev. J.; 24(1):867-874. 
issues determine such as lymphoma, intestinal hemorrhage, or rheumatoid arthritis and access to their treatment respond ${ }^{12}$. Further CRP quantitative studies were applied various methods, including electrochemical immunoassay (ECL), photothermal system (PTB), vertical flow immunoassay (VFA), and so on gained some remarkable results ${ }^{13}$.

This work aims to demonstrate the extraordinary improvement of luminescence signal exploits brought by gold nanoparticles aid for a potential optical biosensor. The Alexa 488 fluorophore molecules stained on CRP are eager to strengthen and stable under the assistance of nano metallic coating.

\section{MATERIALS AND METHOD}

Gold(III) chloride trihydrate $\left(\mathrm{HAuCl}_{4} .3 \mathrm{H}_{2} \mathrm{O}, 99 \%\right)$, sodium citrate tribasic dihydrate $\left(\mathrm{Na}_{3} \mathrm{Ctr}\right)$, 1,4Dioxane $\left(\mathrm{C}_{4} \mathrm{H}_{8} \mathrm{O}_{2}, 99 \%\right)$, succinic anhydride (SA, 99\%), (3-Aminopropyl) triethoxysilane (APTES, 99\%), 11-Mercaptoundecanoic acid (11-MUA, 95\%) were purchased from Sigma-Aldrich, USA. Ethanol $\left(\mathrm{C}_{2} \mathrm{H}_{5} \mathrm{OH}, 99.5 \%\right)$ and methanol $\left(\mathrm{CH}_{3} \mathrm{OH}, 99.5 \%\right)$ were provided from Fisher, USA. Sodium hydroxide $(\mathrm{NaOH})$ was acquired from Guangdong Guanghua Sci-Tech, China. Polydimethylsiloxane (PDMS) was procured from Dow, Korea. C-Reactive Protein/CRP Antibody Alexa Fluor 488 (CRP@Alexa 488) was obtained from Novus Biologicals, USA.

\section{PREPARATION OF GOLD NANOPARTICLES (AU NPS)}

The synthesis of Au NPs was completed by the seedmediated method with NaCtr roled as the reductant for its rapid and simple protocol ${ }^{14}$. A colloidal solution of gold nano seed was quickly assembled at high temperatures by the ingredient reaction. The next stage of growing seed was continuous right after the cooling down period while the light was avoided to prevent photoreduction. The appropriate volume of grown solution was synthesized from the remaining scattering in the ultrasonic bath and finally stored in the required condition.

\section{PREPARATION OF THE MODIFIED SUBSTRATES}

The clean glass substrates underwent a pre-set process of the CUTE plasma cleaner from Femto Science, Korea, for the silanol forming before being treated by $3 \%$ APTES in ethanol to fabricate amine-rich surfaces. Right after, two separate antibody bonding methods were performed. Figure 1a illustrates a five-step no nano metal coating process with the direct antibody linking to the carboxyl from SA treatment. On the other hand, Figure 1 b shows the advanced Au NPs coating process by simply immersion in the nanoparticle storing condition. 11-MUA was used for carboxyl modification after the nanometal middle layer and responded to the CRP@Alexa 488 coupling.

\section{Fabrication of PDMS microfluidic LSPR de- vice}

A PDMS round-shaped mask was placed on the glass substrate after fabrication from mixing the base and the curing agent then heating up to solid ${ }^{15}$. The mask played a role in fitting the light pathway from the optical detection system and limiting chemical loss in the modification.

\section{Analytical Methods}

The optical property of the nanoparticles was analyzed by the V-730 Ultraviolet-visible spectroscopy (UV-Vis) from JASCO, in the range from $400 \mathrm{~nm}$ to $800 \mathrm{~nm}$ for determination of the LSPR accordant maximum absorbance wavelength. The accomplishment of the surface modification was assessed by Fourier-transform infrared spectroscopy (FTIR) by the Vertex $70 \mathrm{v}$ in transmission mode between $4000 \mathrm{~cm}^{-1}$ and $500 \mathrm{~cm}^{-1}$, powder X-ray diffraction (PXRD) by the V8 Advance from Bruker from 35 to 80 degree, the Hitachi 4800 field emission scanning electron microscopy (FESEM) at the scale of $300 \mathrm{~nm}$ and the Euromex OX.2253 PLPHF fluorescence microscopy under the blue light mode with $1 \mathrm{~s}$ of exposure time.

\section{RESULTS}

The Au seed and grown Au NPs performed in the wine red while the seed was darker for its high concentration. Besides, both colloidal solutions were surveyed for the maximum absorbance wavelength by UV-Vis spectroscopy. They showed up at $520 \mathrm{~nm}$ for the seed and $521 \mathrm{~nm}$ for the $40 \mathrm{~min}$ synthesis nanoparticles in Figure 2.

A transmission mode of FTIR was used with each modified step's outcome, including $\mathrm{O}_{2}$ plasma, APTES, SA, and 11-MUA treatment. The range of wavelengths from $4000 \mathrm{~cm}^{-1}$ to $500 \mathrm{~cm}^{-1}$ was observed to record the feature spectrum peaks. Figure 3 shows the FTIR spectra from the measurement of the bonding interaction's oscillation on the silica surface. The crystallite structure and particle shape of the $\mathrm{Au}$ NPs coating surface were examined by the XRD analysis in the angle range from $35^{\circ}$ to $80^{\circ}$ and the FESEM at the scale of $300 \mathrm{~nm}$. In Figure $4 \mathbf{a}$, four peaks presented to four orientations were recorded at about 38 , 


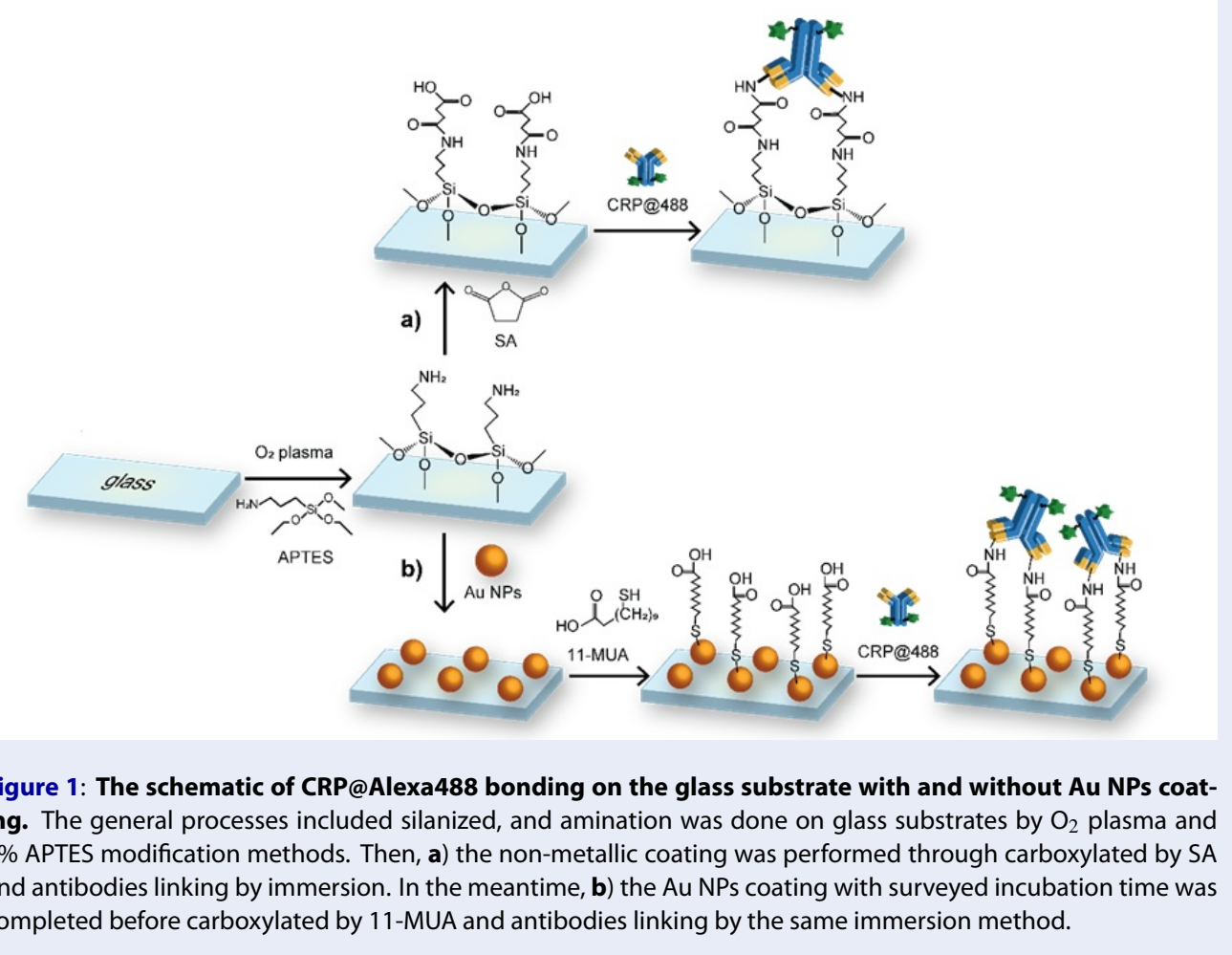

43,62 , and $78^{\circ}$, which was fully described in the Joint Committee's database on Powder Diffraction Standards, USA (JCPDS no. 00-004-0784) ${ }^{16}$.

The Alexa Fluor 488 stained CRP anti-mouse IgG2a incubated over $5 \mathrm{~h}$ on two modified types of glass substrate were observed under a white light mode considered as the blank in Figure 5a-5c, and 1 s exposed blue light mode as the verification of coupling bio-factor appearance in Figure 5b-5d. In one hand of Figure 5ab, the model bonding procedure by SA was performed with fewer and fewer radiation markers localized by the green dots and streaks in which also told an uneven distribution of molecules. On the contrary, a moister, brighter, and denser behavior showed up on the Au NPs inclusion surface via the comparison captures in Figure 5 c-d without changing the biological incubation and fluorescence analysis.

An optical system based on the T-mode (transmission mode) described in the previous study ${ }^{17}$ was used for fluorescence detection and transform into an electric signal. The enhancement factor (EF) of the $\mathrm{Au}$ NPs coated the (1) equation calculated substrates in the mentioned reference. Figure 6 illustrates the fluorescence intensity and enhancement factor recorded from the CRP@Alexa 488 bonding on the comparison coating and non-coating substrate with six different concentrations listed in Table 1.

\section{DISCUSSION}

Due to the Mie theory ${ }^{18}$ about the effects of nanoparticle size on its optical property, the recorded surface plasmon absorbance spectrum at about $520 \mathrm{~nm}$ in the $\mathrm{UV}$-Vis range was coincidental to other studies about the LSPR application in biosensor ${ }^{19}$. Furthermore, the described color was presented to the nanoparticles' size in the range between $20-40 \mathrm{~nm}$, which was pointed out from other researches ${ }^{20}$ and fit with the UV-Vis result.

Four repaired samples had the Si-O-Si asymmetric vibration at around $1060 \mathrm{~cm}^{-1}$ in common since the silica substrate ${ }^{21}$. The broadband at the range of 3485 $\mathrm{cm}^{-1}$ of Figure $3 \mathbf{a}$ is related to the silanol groups' stretching isolated vibration for being treated by $\mathrm{O}_{2}$ plasma $^{22}$. In the case of APTES treatment, the primary amine groups' stretching mode may be noticed at the band of $3362 \mathrm{~cm}^{-1}$. Therefore, its bending and wagging mode also from the $\mathrm{N}-\mathrm{H}$ bonding was shown up at 1562 and $759 \mathrm{~cm}^{-1}$, respectively, in Figure $3 \mathbf{b}^{23}$. The SA and 11-MUA method to form the carboxylate group onto the furthest side of the surface were illustrated in Figure 3c-d. The spectrum of both revealed the broadband of hydroxyl groups stretching mode at around $3410 \mathrm{~cm}^{-1}$ and $3458 \mathrm{~cm}^{-1}$. The 


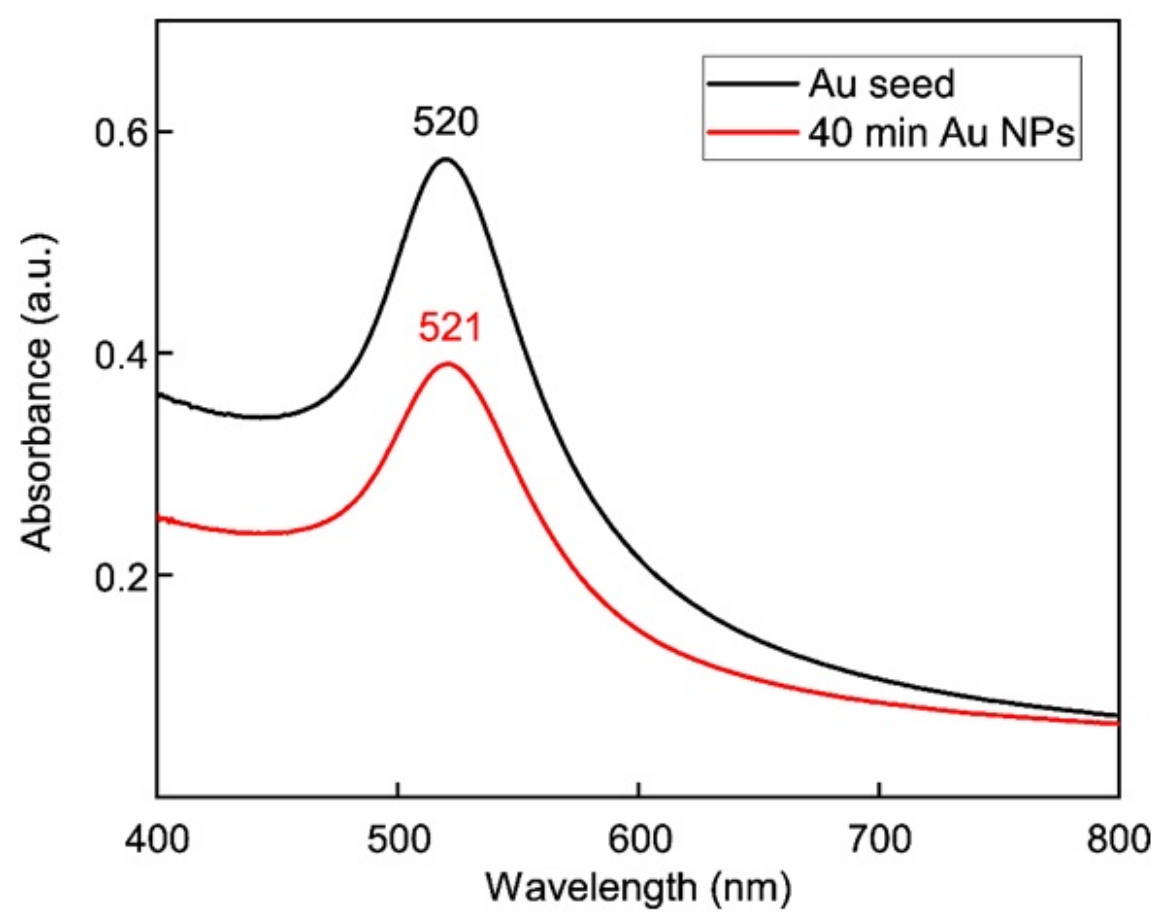

Figure 2: The UV-Vis spectra of Au seed and $\mathbf{4 0}$ min synthesis Au NPs. The Au seed and Au NPs were kept in light-free and $4^{\circ} \mathrm{C}$ conditions before diluted to analyze and performed the absorbance at 520 and $521 \mathrm{~nm}$, respectively.

Table 1: The EF and CV of the examined samples were based on the antibody concentration.

\begin{tabular}{|c|c|c|c|c|}
\hline $\begin{array}{l}\text { CRP concentra- } \\
\text { tion } \\
(\mathrm{mg} / \mathrm{mL})\end{array}$ & $\begin{array}{l}\text { Fluorescence intensity } \\
\text { of non-Au NPs coating } \\
(\mu \mathrm{W})\end{array}$ & $\begin{array}{l}\text { Fluorescence inten- } \\
\text { sity of Au NPs coat- } \\
\text { ing }(\mu \mathrm{W})\end{array}$ & $\begin{array}{l}\text { Enhancement factor } \\
\text { (fold) }\end{array}$ & $\begin{array}{l}\text { Coefficient of varia- } \\
\text { tion } \\
(\%)\end{array}$ \\
\hline 0.01 & 0.20024 & 0.94225 & 4.9 & 0.06 \\
\hline 0.03 & 0.23321 & 1.06793 & 4.7 & 0.03 \\
\hline 0.05 & 0.27692 & 1.232415 & 4.6 & 0.7 \\
\hline 0.1 & 0.29209 & 1.372065 & 4.8 & 0.3 \\
\hline 0.3 & 0.30839 & 1.464335 & 4.8 & 0.04 \\
\hline 0.5 & 0.33479 & 1.575505 & 4.8 & 0.3 \\
\hline
\end{tabular}

other stretching mode vibrations of $\mathrm{C}=\mathrm{O}$ and $\mathrm{C}-\mathrm{O}$ oscillations illustrated at the peaks of 1695,1701 , and $1450,1467 \mathrm{~cm}^{-124}$. The double peaks at 2922 and $2850 \mathrm{~cm}^{-1}$ noticed in Figure $3 \mathbf{d}$ were assigned to the alkynes bonding from the MUA substances structure, which were the asymmetric and symmetric stretching modes. The familiar peaks are either APTES and SA spectrum but single and weaker since the shorter carbon chains ${ }^{25,26}$.

Otherwise, the nanospheres showed up on the coated after being affected by the microscopy electron beam.
In detail, the face-centered cubic (FCC) structure of pure crystalline gold has appeared for the Bragg reflection. The (111) orientation got the strongest intensity of all, while the other recorded three, including (200), (220), and (311) had an approximately equal intensity. However, the most promising signal over the different immersion times was in the $16 \mathrm{~h}$ Au NPs coating surface, although the spectrum underwent a trend of increase. By using the Scherrer equation in calculating the crystalline size ${ }^{27}$ after the spectra of the (111) orientation, the size is more or less $21.5 \mathrm{~nm}$. 


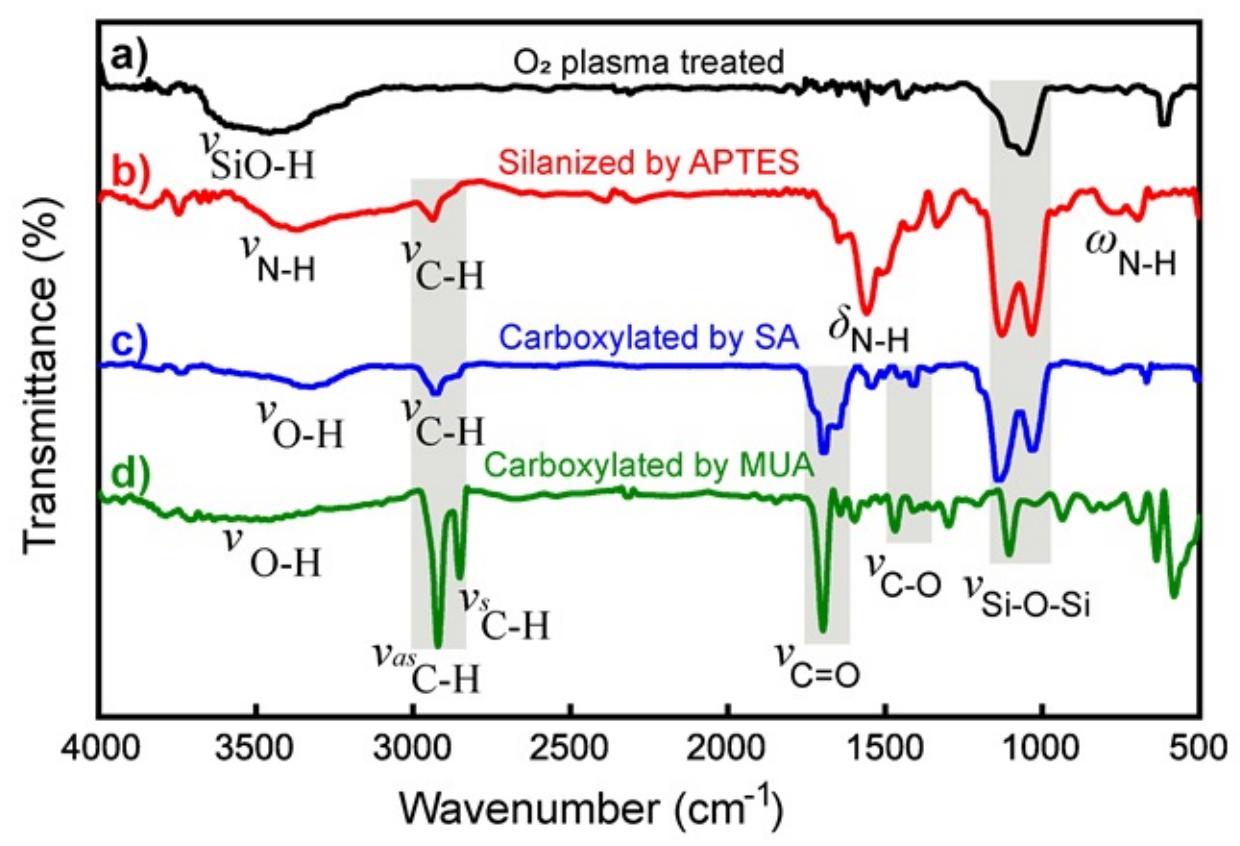

Figure 3: The FTIR spectra of the modified substrates. The same modification processes were repeated on silica monocrystalline silicon substrates for the transmission analysis mode of the bonding interaction after a) $\mathrm{O}_{2}$ plasma treatment, b) APTES treatment, c) SA treatment and, d) 11-MUA treatment. The results represented the corresponding stretching and bending vibration of the required organic group, such as SiO-H of silanol, $\mathrm{N}-\mathrm{H}$ of amine, and - $\mathrm{COOH}$ of carboxylic.
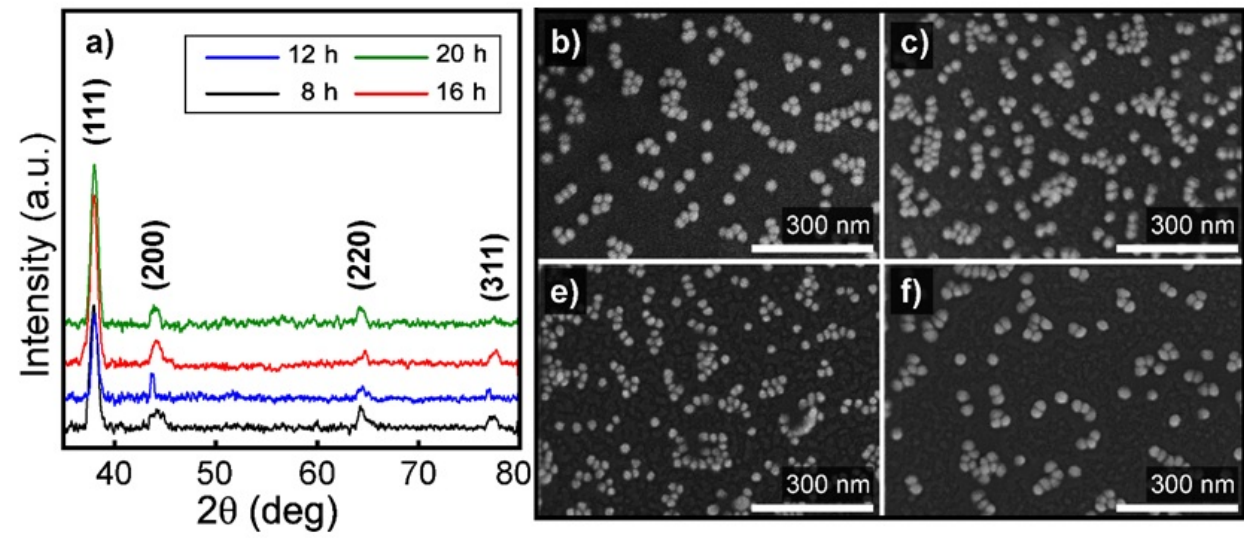

Figure 4: The XRD spectra and FESEM capture of Au NPs coating glass by time. A catalyze of Ni-filtered Cu in the X-Ray diffraction, and a $300 \mathrm{~nm}$ length scale of magnification in the FESEM was used for: a) investigating the crystallite structure and particles appearance after the Au NPs immersion of b) 8, c) 12, d) 16 and, e) $20 \mathrm{~h}$. The XRD result of 4 particular orientations of gold crystallite at around $38^{\circ}, 43^{\circ}, 62^{\circ}$, and $78^{\circ}$, then clearly spherical nanostructure of them at the size about 20 to $40 \mathrm{~nm}$ under FESEM analysis was proved the successful synthesis and coating. 

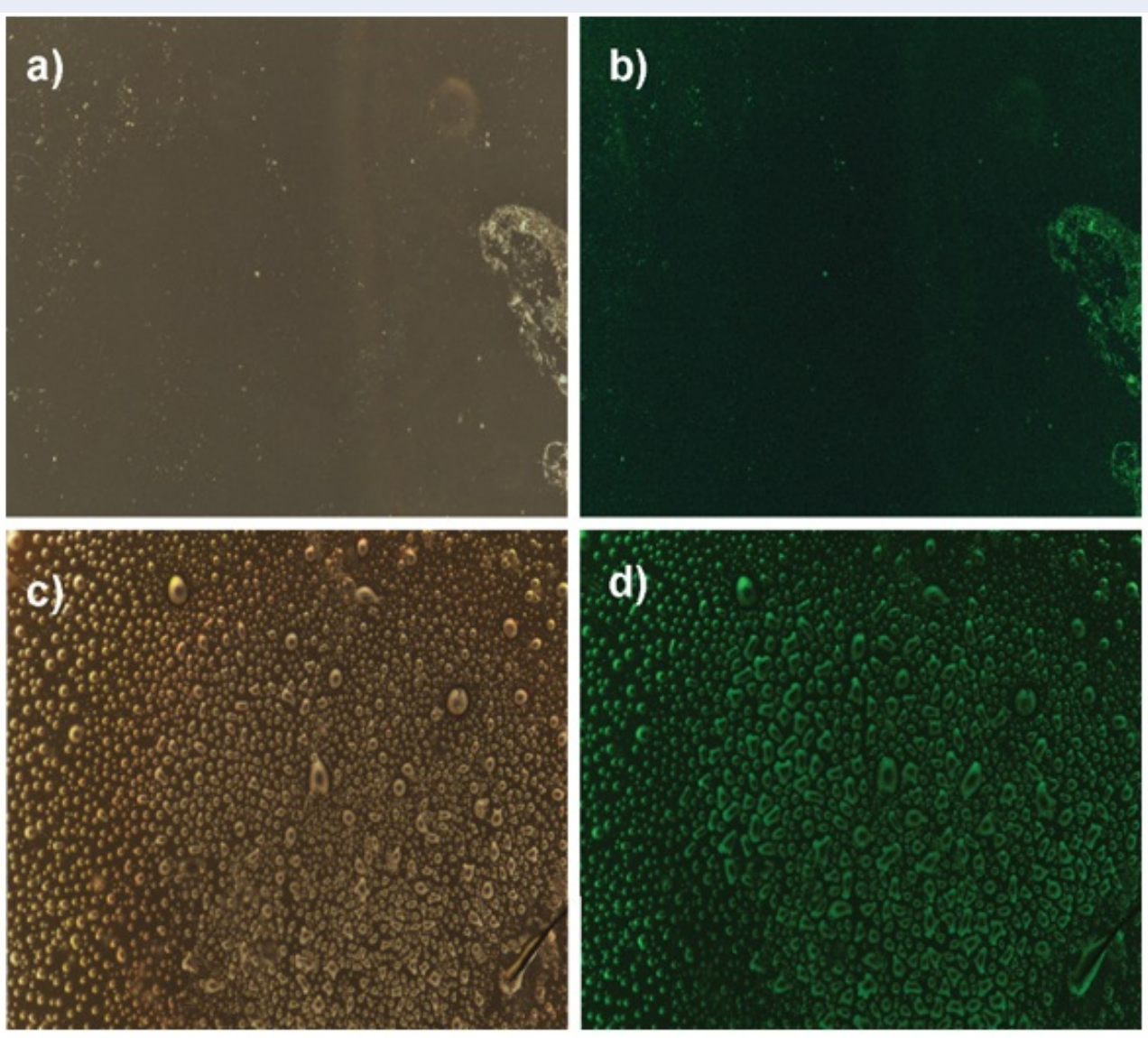

Figure 5: The fluorescence microscopy images of CRP@488 bonding samples. The different light modes were used in recognition of the fluorescence dyed antibodies on no Au NPs coating glass under a) white light, b) $1 \mathrm{~s}$ exposure blue light, and Au NPs coating glass under c) white light, and d) $1 \mathrm{~s}$ exposure blue light. Under the excitation blue light, the dye of antibodies succeed linking on the modified Au NPs coating substrates was performed its enhanced fluorescence compared to the non-coating.

It also coincided with the FESEM captures considered by the nanoparticle's uniformity and the surface arrangement. By comparison with the nanoscale, the sphere's size is between $20 \mathrm{~nm}$ and $40 \mathrm{~nm}$ and consistent with the other analysis as UV-Vis and XRD. Figure $4 \mathbf{b}$ of $8 \mathrm{~h}$ immersion of Au NPs shows a lower density of nanospheres formed on the surface than the others. Figure 4 c-e speak for 12,16 , and $20 \mathrm{~h}$ immersion, the selected $16 \mathrm{~h}$ meet the need for a convenient experimental time and the required about the space distributed.

As the desired LSPR effect on the optical signal enhancement from the advanced metal nanoparticles, the result assumed from the visible images presents a successful immobilization through both fabrications within the major domination in magnification light emission of the synthesized gold nanoparticles. Figure $5 \mathbf{b}$-d shows the photo taken to confirm the flu- orescence's green color from the fluorophores Alexa 488 conjugated with the CPR used in two different configuration coating (pristine glass and AuNPscoated glass). This allows the visual check-up of the fluorescence under ultraviolet light excitation and leads us to determine the CPR concentration appropriate for clarifying the significant difference between the no coat and AuNPs-coat amplifications.

An similar trend of the increase happened in both methods, but a sharper shape can be mentioned by the Au NPs coating one. The no Au coating samples give the power under $0.4 \mu \mathrm{W}$ while the coated reaches the peaks from 1 to $1.5 \mu \mathrm{W}$. Figure $6 \mathbf{b}$ presents the enhancement factor caused by the LSPR effect as desired, and the average 4.8 fold multiplication has occurred. The maximum enhancement resulted is in $0.01 \mathrm{mg} / \mathrm{mL}$ binding antibody and dropped slightly when it comes to 0.05 which the experimental manip- 

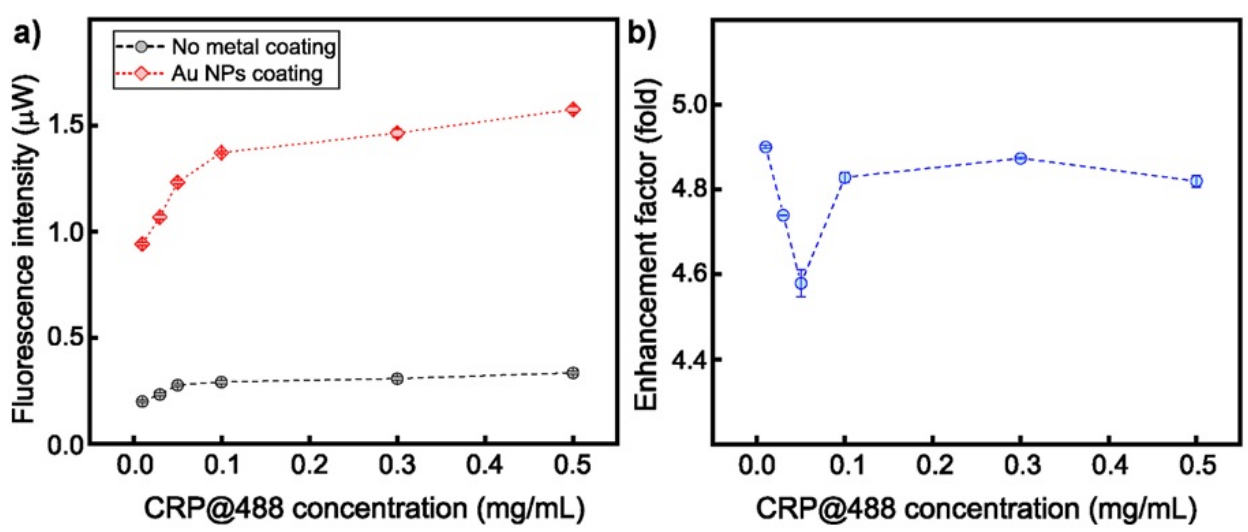

Figure 6: The fluorescence intensity and enhancement factor of CRP@488 detection by Au NPs coating substrates. The detecting solution of antibodies was prepared into different concentrations of $0.01,0.03,0.05,0.1$, 0.3 and $0.5 \mathrm{mg} / \mathrm{mL}$. a) The fluorophore signal gathered from the compared substrates of Au NPs coating and noncoating was recorded under excitation light. b) The calculated enhanced factor at about 4.8 folds throughout the detection of 6 examined CRP@488 solutions.

ulation may cause. It almost remained throughout the 10 times higher and more concentration that may be responsible for the limited carboxyl modified groups in the chamber work area. The LOD for this detection experiment can be accounted for $0.01 \mathrm{mg} / \mathrm{mL}$, which is 100 times lower than the standard of CRP low-risk announcement at $1 \mathrm{mg} / \mathrm{L}$ (published in 2003 by The American Heart Association and U.S. Centers for Disease Control and Prevention), and much higher than the earlier research based on lossy-mode resonance (LMR) fiber devices ${ }^{28}$. The coefficient of variation $(\mathrm{CV})$ was shown in Table 1 after 4 times repeat from each sample, demonstrating the repeatability and ideal if under $0.5 \%$. The $0.05 \mathrm{mg} / \mathrm{mL}$ sample had a higher $\mathrm{CV}$ at $0.7 \%$, which coincided with the lower EF unexpectedly.

\section{CONCLUSIONS}

The gold nanoparticles synthesized from the seedmediate method was proved the strong LSPR effect on the enhancement of the fluorescence signal. Besides, a simple and effective modification protocol was performed aimed to coat Au NPs and to bond the biofactor. The accomplished substrate pattern was built prepared for sensing through the curtain analysis of FTIR, XRD, FESEM, and fluorescence microscopy. As expected, a high sensitivity optical biosensor based on LSPR was designed and fabricated that got the remarkable EF at 4.8 folds with a low $\mathrm{CV}$ at $0.7 \%$. There is an auspicious prospect in the ability of other noble metals utilization, switching into others structure or size, and a combination of various optical phenomena for the applications.

\section{ABBREVIATIONS}

11-MUA: 11-Mercaptoundecanoic acid APTES: 3-(Triethoxysilyl)Propylamine Au NPs: Gold nanoparticles CRP: C-Reactive protein CV: Coefficient of variation DI: Deionized water

FESEM: Field emission scanning electron microscope FTIR: Fourier-transform infrared spectroscopy

LSPR: Localized surface plasmon resonance PDMS: Polydimethylsiloxane

SA: Succinic anhydride

UV-Vis: Ultraviolet-visible

WCA: Water contact angle

XRD: X-Ray diffraction

\section{COMPETING INTEREST}

The author(s) declare that they have no competing interests.

\section{AUTHORS' CONTRIBUTION}

All the authors read and corrected the submitted final version.

Phuong Que Tran Do and Tran Duc Trung has conceived experiments design, analyzed data, carried out, and written the manuscript with support from Dr. Nhu Hoa Thi Tran.

Bach Thang Phan, Hanh Kieu Thi Ta, Ngoc Xuan Dat Mai carried out the experiments in group

Lai Thi Hoa, Thanh Van Thi Tran, Dung Van Hoang have supported the analysis techniques. Dr. Nhu Hoa Thi Tran revised and corrected the manuscript. 


\section{ACKNOWLEDGEMENT}

This research is funded by Vietnam National Foundation for Science and Technology Development (NAFOSTED) under grant number 103.03-2019.379. I would like to gratefully acknowledge the Vietnam National University in Ho Chi Minh City to Center for Innovative Materials and Architectures (Laboratory for Optics and Sensing).

\section{REFERENCES}

1. Yang G, Xiao Z, Tang C, Deng Y, Huang H, He Z. Recent advances in biosensor for detection of lung cancer biomarkers. Biosens Bioelectron. 2019;141:111416. PMID: 31279179. Available from: https://doi.org/10.1016/j.bios.2019.111416.

2. Li CC, Wang ZY, Wang LJ, Zhang CY. Biosensors for epigenetic biomarkers detection: A review. Biosens Bioelectron. 2019;144:111695. PMID: 31526982. Available from: https: //doi.org/10.1016/j.bios.2019.111695.

3. Goode JA, Rushworth JVH, Millner PA. Biosensor Regeneration: A review of common techniques and outcomes. Langmuir. 2015;31:6267-6276. PMID: 25402969. Available from: https://doi.org/10.1021/la503533g.

4. Zhang YX, Wang YH. Nonlinear optical properties of metal nanoparticles: A review. RSC Adv 2017;7:4512945144;Available from: https://doi.org/10.1039/C7RA07551K.

5. Boken J, Khurana P, Thatai S, Kumar D, Prasad S. Plasmonic nanoparticles and their analytical applications: A review. Appl Spectrosc Rev 2017;52:774-820;Available from: https://doi. org/10.1080/05704928.2017.1312427.

6. David A. Vanden Bout. Metal nanoparticles: synthesis, characterization, and applications. Journal of the American Chemical Society 2002;26:7874-7875;Available from: https://doi.org/10. 1021/ja015381a.

7. John Turkevich B, Cooper Stevenson P, Hillier J A study of the nucleation and growth processes in the synthesis of colloidal gold Royal Society of Chemistry 1951;47:0366-9033;Available from: https://doi.org/10.1039/df9511100055.

8. Unser S, Bruzas I, He J, Sagle L. Localized surface plasmon resonance biosensing: Current challenges and approaches. Sensors (Switzerland). 2015;15:15684-15716. PMID: 26147727. Available from: https://doi.org/10.3390/s150715684.

9. Peng J, Xu X, Tian Y, Wang J, Tang F, Li L. Improved efficiency in polymer light-emitting diodes using metal-enhanced fluorescence. Appl Phys Lett. 2014;105:173301. Available from: https://doi.org/10.1063/1.4901042.

10. Lee KS, El-Sayed MA. Gold and silver nanoparticles in sensing and imaging: Sensitivity of plasmon response to size, shape, and metal composition. J Phys Chem B 2006;110:1922019225;PMID: 17004772. Available from: https://doi.org/10. 1021/jp062536y.

11. Sepúlveda $B$, Angelomé PC, Lechuga LM, Liz-Marzán LM LSPR-based nanobiosensors. Nano Today. 2009;4:244-251. Available from: https://doi.org/10.1016/j.nantod.2009.04.001.

12. Sproston NR, Ashworth JJ. Role of C-reactive protein at sites of inflammation and infection. Front Immunol 2018;9:754;PMID: 29706967. Available from: https://doi.org/10.3389/fimmu. 2018.00754.

13. Guo L, Yang Z, Zhi S, Feng Z, Lei C, Zhou Y. A sensitive and innovative detection method for rapid $C$-reactive proteins analysis based on a micro-fluxgate sensor system. PLoS One. 2018;13. PMID: 29601593. Available from: https://doi.org/10. 1371/journal.pone.0194631.

14. Do PQT, Huong VT, Phuong NTT, Nguyen $\mathrm{T}-\mathrm{H}$, Ta HKT, Ju H, et al. The highly sensitive determination of serotonin by using gold nanoparticles (Au NPs) with a localized surface plasmon resonance (LSPR) absorption wavelength in the visible region. RSC Adv 2020;10:30858-30869;Available from: https://doi.org/ 10.1039/D0RA05271J.

15. Huong VT, Van Tran V, Lee NY, Van Hoang D, Loan Trinh KT, Phan TB, Tran NHT. Bimetallic thin-film combination of surface plasmon resonance-based optical fiber cladding with the polarizing homodyne balanced detection method and biomedical assay application. Langmuir;2020;36:99679976;PMID: 32787053. Available from: https://doi.org/10. 1021/acs.langmuir.0c01793.

16. Oint committee on powder diffraction standards. Analytical Chemistry 1970;11:81A-81A;Available from: https://doi.org/ 10.1021/ac60293a779.

17. Tran NHT, Trinh KTL, Lee JH, Yoon WJ, Ju H. Reproducible enhancement of fluorescence by bimetal mediated surface plasmon coupled emission for highly sensitive quantitative diagnosis of double-stranded DNA. Small 2018;14:1801385;PMID: 30003662. Available from: https://doi.org/10.1002/smll. 201801385.

18. Hergert W, Wriedt T. The Mie theory. Springer Series in Optical Sciences;2012:53-71;Available from: https://doi.org/10.1007/ 978-3-642-28738- 1 .

19. Oh SY, Heo NS, Shukla S, Cho HJ, Vilian ATE, Kim J, et al. Development of gold nanoparticle-aptamer-based LSPR sensing chips for the rapid detection of Salmonella typhimurium in pork meat. Sci Rep 2017;7:10130;PMID: 28860462. Available from: https://doi.org/10.1038/s41598-017-10188-2.

20. Dutta S, Saikia K, Nath P. Smartphone based LSPR sensing platform for bio-conjugation detection and quantification. RSC Adv 2016;6:21871-21880;Available from: https://doi.org/ 10.1039/C6RA01113F.

21. Tran NHT, Kim J, Phan TB, Khym S, Ju H. Label-free optical biochemical sensors via liquid-cladding-induced modulation of waveguide modes. ACS Appl Mater Interfaces 2017;9:3147831487;PMID: 28849907. Available from: https://doi.org/10. 1021/acsami.7b09252.

22. Khan AS, Khalid H, Sarfraz Z, Khan M, Iqbal J, Muhammad $\mathrm{N}$, et al. Vibrational spectroscopy of selective dental restorative materials. Appl Spectrosc Rev 2017;52:507-540;Available from: https://doi.org/10.1080/05704928.2016.1244069.

23. Majoul N, Aouida S, Bessaïs B. Progress of porous silicon APTES-functionalization by FTIR investigations. Appl Surf Sci 2015;331:388-391;Available from: https://doi.org/10.1016/ j.apsusc.2015.01.107.

24. Amoli BM, Gumfekar S, Hu A, Zhou YN, Zhao B. Thiocarboxylate functionalization of silver nanoparticles: Effect of chain length on the electrical conductivity of nanoparticles and their polymer composites. J Mater Chem 2012;22:2004820056;Available from: https://doi.org/10.1039/c2jm33280a.

25. Jiang S, Dai L, Qin Y, Xiong L, Sun Q. Preparation and characterization of octenyl succinic anhydride modified taro starch nanoparticles. PLoS One 2016;11: e0150043;PMID: 26918568. Available from: https://doi.org/10.1371/journal.pone.0150043.

26. Bordbar AK, Rastegari AA, Amiri R, Ranjbakhsh E, Abbasi $M$, Khosropour AR. Characterization of modified magnetite nanoparticles for albumin immobilization. Biotechnol Res Int 2014;2014:1-6;PMID: 24963410. Available from: https://doi. org/10.1155/2014/705068.

27. Julian RHR. Catalyst Characterization. Elsevier;2019:12132;PMID: 30747781. Available from: https://doi.org/10.1016/ B978-0-444-63474-0.00005-9.

28. Zubiate P, Zamarreño CR, Sánchez P, Matias IR, Arregui FJ. High sensitive and selective $C$-reactive protein detection by means of lossy mode resonance based optical fiber devices. Biosens Bioelectron 2017;93:176-181;PMID: 27638106. Available from: https://doi.org/10.1016/j.bios.2016.09.020. 